\title{
Correction to: \\ Effects of Gender and Relationship Type on the Response to Artificial Intelligence by Kim A, Cho M, Ahn J, and Sung Y. Cyberpsychol Behav Soc Netw. 2019;22(4):249-253. DOI: $10.1089 /$ cyber.2018.0581
}

N THE APRIL 2019 issue of Cyberpsychology, Behavior, and Social Networking (vol. 22, no. 4; 249-253), the article titled Effects of Gender and Relationship Type on the Response to Artificial Intelligence by Kim A, Cho M, Ahn J, and Sung Y requires a correction because the authors inadvertently excluded funding information from the Acknowledgment section.

The Acknowledgment section should have read as:

This research was supported by the Ministry of Education of the Republic of Korea and the National Research Foundation of Korea (NRF-2016S1A3A2924760).

The online version of the article has been corrected to reflect this change.

The authors apologize for the omission. 